\title{
Engagement in Practice: Academic Service in a Sophomore-level Mechanical Engineering Measurements Lab
}

\section{Dr. Ines Basalo, University of Miami}

Dr. Basalo is an Assistant Professor in Practice in Mechanical and Aerospace Engineering at the University of Miami. Prior to joining the University of Miami in 2014, she worked as an adjunct professor at Columbia University and the Cooper Union in New York City. She received her PhD from Columbia University in 2006, where her research focused on the mechanical and frictional properties of articular cartilage. Dr. Basalo 's teaching experience includes Thermodynamics, Computer Graphics, Materials Science and laboratory courses. Since 2015 she has been actively involved in the University of Miami College of Engineering's "Redefining Engineering Education" strategic plan on educational innovation. As part of this plan, Dr. Basalo worked with 2 other faculty members to organize inaugural Senior Design Expo in May 2017, an exposition where over 200 senior students showcased their Capstone projects to the University of Miami community, alumni and industry leaders. Starting in 2016 and through her work with the University of Miami's Engaged Faculty Fellowship program, Dr. Basalo incorporated an academic service component into the final project for a sophomore-level Measurements Lab course.

\section{Dr. Jonathon Anthony Toft-Nielsen, University of Miami}

Jonathon Toft-Nielsen completed his Ph.D. in Biomedical Engineering at the University of Miami in 2012. Since graduating, he has maintained positions both in industry and academic, working at a small medical device company in South Miami (Intelligent Hearing Systems) and with an adjunct position at the University of Miami's College engineering. He strives to continually improve engineering education through his involvement in a number of courses in both the Mechanical and Biomedical Engineering Departments.

\section{Dr. Scotney D. Evans, University of Miami}

Dr. Evans is an Associate Professor in the Department of Educational and Psychological Studies in the School of Education and Human Development and Acting Director of the Office of Civic and Community Engagement. He teaches and advises students in the undergraduate program in Human and Social Development (HSD), the master's program in Community and Social Change (CSC), and the PhD program in Community Well-being (CWB). He is a community-engaged researcher working to understand and support the role of community-based organizations, networks, and coalitions in building collective power to promote community wellbeing, social change, and social justice. Dr. Evans is also the editor of the online journal Collaborations: A Journal of Community-Based Research and Practice. 


\section{Engagement in Practice: Incorporating Service-Learning in a Mechanical Engineering Measurements Lab - A Case Study}

\section{Introduction}

The purpose of service-learning is to provide students with a connection between the classroom and their community with a reflection component involved [1]. However, despite evidence pointing to deeper learning and development of critical thinking skills when enough opportunity for reflection is included in service-learning [2]-[3], reflection is not widely used in engineering [3]. This study describes the incorporation of service-learning into an existing group project in an undergraduate mechanical engineering measurements lab at the University of Miami in the fall semester of 2017, and how reflection was used to allow students to make a connection between the course concepts and their community, and to examine their own sense of civic responsibility.

\section{Background}

Measurements lab is a 3-credit required course for sophomores in mechanical and aerospace engineering at the University of Miami's College of Engineering. Students learn the basic principles of measurements, data interpretation and uncertainty analysis. Enrollment varies between 20 and 40 students, as the class is offered both semesters in the academic year.

In the fall semester of 2014 a final group project was incorporated to provide students the opportunity to work in an open-ended activity. Students had to formulate a hypothesis and design a simple experiment to prove this hypothesis using a sensor that works with the Arduino microcontroller. Students worked on this project during the last 4 weeks of the semester and were required to write a technical report and create a poster.

Initially there were no constraints on the topic, apart from approval by the instructor. After 3 semesters, the instructor noticed that the topic of many projects was related to issues that are part of the students' daily life on campus. Examples include a study of mold growth conditions in one of the residential colleges using a humidity/temperature sensor, an analysis of the idle vibration on the shuttle buses using an accelerometer, and a comparison of the noise levels at popular study areas in the main library with a sound sensor. These projects had generated data that could easily be shared with and utilized by community partners on campus, therefore the incorporation of a service-learning component seemed a natural fit.

\section{Project Design}

The final project was modified in the fall semester of 2016 with the help of the University of Miami's Office of Civic and Community engagement. This office awards 5 summer stipends to faculty across the university who commit to incorporate civic engagement and service-learning components into new or existing courses. The program is designed to promote the integration between research, teaching and service and to foster collaborations between the university and the community. Fellows participate in workshops about practices in civic engagement and service-learning, and work with the support of the staff to modify their courses.

Additional requirements added to this project were: (1) project topic must relate to a problem/issue on campus, (2) students must reach out and communicate with the relevant office at the university (i.e. facilities, classroom management, etc.), and (3) report must include recommendations and action items based on the analysis of collected data. 
The new learning outcomes of the project are that, upon completion of the project, students should be able to:

1. Design an experiment with the purpose to test a hypothesis

2. Apply the knowledge learned in class to a situation outside of the classroom

3. Offer recommendations based on the analysis of the data gathered during the project

4. Value the importance of being a contributing member of the community

\section{Project Timeline}

Table 1 shows an example of the modified course schedule, with the activities related to the final project on the first column. One lab activity was eliminated and the rest were scheduled earlier in the semester to allow students to work exclusively on this project during the last 6 weeks.

\begin{tabular}{|c|c|c|}
\hline Week & Final Project Task & Other Topics and Activities \\
\hline 1 & - Introduction to the final project & $\begin{array}{l}\text { - Syllabus discussion } \\
\text { - } \quad \text { Introduction to measurements }\end{array}$ \\
\hline 2 & 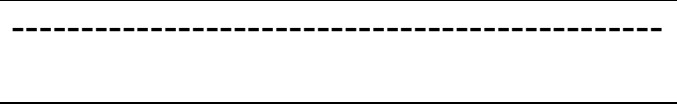 & $\begin{array}{l}\text { - Review of hypothesis testing } \\
\text { - } \quad \text { Lab \#1 }\end{array}$ \\
\hline 3 & 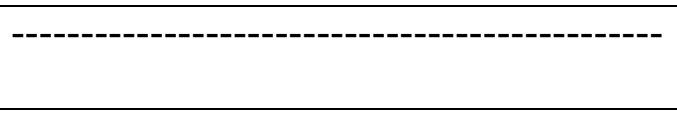 & $\begin{array}{ll}\text { - } & \text { Writing laboratory reports } \\
\text { - } & \text { Uncertainty Analysis } \\
\end{array}$ \\
\hline 4 & ----------------------------------------------------- & $\begin{array}{l}\text { - Graphical communication } \\
\text { - } \quad \text { Lab \#2 }\end{array}$ \\
\hline 5 & $\begin{array}{l}\text { - Groups are selected } \\
\text { - Students brainstorm to select topic }\end{array}$ & $\begin{array}{ll}\text { - } & \text { Error propagation } \\
\text { - } & \text { Writing technical memos } \\
\end{array}$ \\
\hline 6 & --------------------------------------------------- & $\begin{array}{l}\text { - Review of Linear Regression } \\
\text { - } \quad \text { Lab\# } 3\end{array}$ \\
\hline 7 & $\begin{array}{ll}\text { - } & \text { Topic approved by instructor } \\
\text { - } & \text { Students receive sensor } \\
\end{array}$ & - Creating effective posters \\
\hline 8 & $\begin{array}{l}\text { - } \quad \text { Start background research } \\
\text { - } \quad \text { Draft of experimental protocol }\end{array}$ & - $\mathrm{Lab} \# 4$ \\
\hline 9 & $\begin{array}{l}\text { - Finalize background research } \\
\text { - Pre-flection }\end{array}$ & ---------------------------------------- \\
\hline 10 & - Finalize experimental protocol & 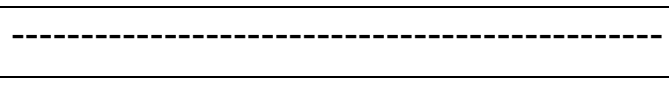 \\
\hline 11 & - Data collection & --------------------------- \\
\hline 12 & $\begin{array}{l}\text { - Data collection } \\
\text { - } \quad \text { Data analysis } \\
\end{array}$ & |-------------------------------------------- \\
\hline 13 & - Data analysis & 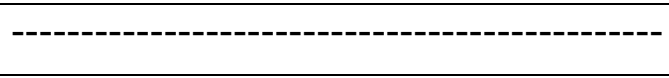 \\
\hline 14 & - Finalize report and poster & 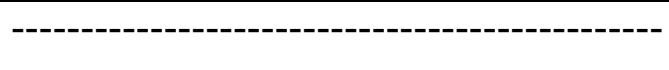 \\
\hline 15 & $\begin{array}{ll}\text { - } & \text { Final Reflection } \\
\text { - } & \text { Report and poster due } \\
\end{array}$ & ---------------------------------------------------- \\
\hline
\end{tabular}

Table 1. Final project timeline based on a typical 15-week semester. Note that the items listed on the Other Topics and Activities column are not necessarily covered in that order every semester. 


\section{$\underline{\text { Reflection Activities }}$}

A two-part reflection assignment (before service and after service) was incorporated to give students the opportunity to first examine their assumptions about the work outside the classroom and then look back and analyze these assumptions once the project is over, when they are asked explicitly to link their experience with the academic content of the course [2]. The design and execution of these two reflection activities was done based on documented "tips \& tricks" [4], collected from conversations with educators who had shared their reflection activities through the Consortium to Promote Reflection in Engineering (CPREE) [5].

The reflection before community service ("pre-flection") consists of 4 questions (see Table 2) and is to be done early in the project timeline, after students pick the topic of the project and identify the objective but before they start working on it. The main purpose of the pre-flection is to help students reflect on their role as members of a community (questions 1 and 3), to help them identify their assumptions about working outside the classroom (question 4), and to create a personal goal describing what they hope to learn (question 2).

1. Do you think engineers should be active in their community? Why or why not?

2. Now think carefully about the specific objective of your project and who will benefit from the information collected after completing the project. Do you expect that this project will affect the way you see your role as a member of the UM community? Why?

3. Write a personal goal statement for this project that describes what you hope to learn in the next 6 weeks while you work on your final project.

4. Think of your project and the sensor you will be using. What specific problems/concerns do you expect to arise as you work on your project? Examples are: technical issues with the sensor, environmental conditions that will prevent you from measuring variables, accessibility to the site where you will be taking measurements, personal issues, potential conflicts with other group members etc. Please be specific.

Table 2. Pre-flection questions

The reflection after service ("final reflection") is to be done at the end of the semester, ideally on the last day of class when the students have collected all data. Questions are shown in Table 3. The purpose of the final reflection is to make students review the expectations they had at the start of the project and compare them with the actual experience (questions 1 and 3), identify which concepts learned in class they applied while working on the project (question 2), and think of specific examples of how they can contribute to their community on campus (question 4). 
1. You had to write a personal goal statement for your "preflection". Did you learn everything you expected to learn while working on this project? More? Less? Explain your answer.

2. Give specific examples of how you applied the concepts you learn in this class during the lectures and the labs on the final project. Those concepts include statistical concepts, error analysis and communication (writing) skills.

3. In the preflection you also had to describe the problems you expected to face during your project. Did you encounter all those issues? Did any new issues arise? Explain.

4. How do you think engineering students could become active and contributing members of the University of Miami community? Please give specific examples.

\section{Table 3. Final reflection questions}

\section{Project Execution}

The modified project was first implemented in the fall semester of 2017, when the class had 21 students in mechanical and aerospace engineering: 3 sophomores, 11 juniors and 8 seniors (status is determined by number of credits; 7 out of the 8 seniors were starting their third year). Students selected their own group of 3 , for a total of 7 groups. The list of projects was as follows:

- A study of noise pollution generated by the landscapers near a classroom building

- Identification of ideal location for studying on two floors of the main library by analyzing sound levels during popular study times

- A comparison of the intensity of UV rays and temperature in different locations at the students' activity center

- A study of the availability of training equipment by tracking the number of people entering the gym during peak hours

- A comparison of noise levels in two popular study locations on campus

- A test of the effectiveness of air curtains in the doors of a dining hall on maintaining lower temperatures indoors

Students worked exclusively on the project during the last 6 weeks of the semester (see Table 1). The twice-weekly 50-minute lecture time was used by the instructor to give feedback on experimental design and technical writing. Students were asked to start working on the report early on, and to collaborate using Google Docs. The instructor had access to all the documents and continually offered feedback, in and outside of the classroom. The 2.75-hour weekly lab time was dedicated to data collection and sensor troubleshooting.

Students worked on the reflection activities in class to encourage spending quality time understanding the questions and articulating their answers. They had about 40 minutes to complete each reflection activity after the instructor provided detailed instructions. Answers were collected electronically through Blackboard Learn. Reflection activities were not graded.

\section{Preliminary Analysis of Reflection Activities}

In the pre-flection, a recurring topic in the answer to question 1 was the role of engineers as not only problem solvers, but also as problem identifiers: "engineering students can find different kinds of problems around campus and give suggestions on how to solve them ", "we need to pay more attention to the things around us to see if there is something that needs to be improved", "by taking it upon themselves to collect data of things they find interesting, engineering students 
may improve certain aspects of the campus and community". In terms of their personal goals (question 2 of pre-flection) many students demonstrated a desire to work as part of a team: "to get experience as a team member", "to refine my teamwork skills". Also, improving communication skills was a common answer ("to develop technical skills further", "to develop good thought and possible solution presenting skills"). Many students articulated how the project would impact their own lives, which shows that they had a personal interest in the project. This was not unexpected, as the topic of the project was selected by each group.

In the final reflection, answers to question 2 (Table 3 ) seem to indicate that students could articulate their understanding of the material discussed in class. Many provided specific examples of which concepts they applied during the project: "we performed the analysis to determine the uncertainties in our temperature and UV measurements", "we calculated the bias and precision error to find the total value of the error", "these concepts helped me to understand how error is calculated and where error in data comes from". Answers to question 4 made it clear that students really thought about the impact engineers can have in their community: "by becoming more involved in the campus community, engineering students could help set an example for other students to follow, and this way we can all leave our small contribution into making the university a better place for everyone", "All it takes for change is for one person to think or do something differently", "We have a wide range of studies involving math and science and we can greatly influence others by communicating and educating", "Engineers are some of the most creative and innovative people in the world, and I think they have a responsibility to think outside of the box for new solutions that will make the community better".

\section{Lessons Learned: Challenges and Rewards}

The main challenge was making sure students were aware of the service-learning aspect of the project. Most groups worked very well around this, and understood the value of what they were doing and reached out to those relevant parties on campus. But a few groups worked in isolation from these potential partners and based their experiment and recommendations on assumptions of what the potential partners would like to know. One way to avoid this issue could be to ask students to approach potential community partners earlier in the semester, as early as week 5 when they pick the topic (see Table 1) and to have the instructors involved in this process. Another challenge was getting every student to truly think about the purpose of the questions and to provide meaningful answers. For example, in question 2 of the pre-flection (Table 2) many students' answers about their personal goals were a simple reverberation of the project objectives, and they did not inquire deeper into their personal objectives. This can be fixed by changing the wording in the reflection questions, asking students to give specific examples (like in question 4 of the pre-flection and question 2 of the final reflection) and to ask them to avoid certain answers (i.e. personal goals are different from the project objective).

The main reward was to see how students thought broadly about their role in the University of Miami community. The groups that successfully approached the potential partners on campus were able to establish ongoing conversations about their project and to offer specific recommendations. It was gratifying to see that students took the reflection seriously and that they went beyond what was asked. For example, in question 4 of the final reflection many offered suggestions, even if this was not explicitly asked in the question: "students could poll the community about issues or problems they have discovered", "the college of engineering itself could host annual events that aim to contribute to our community", "we can write articles and we can do videos/blogs of engineering applications in the real world". Another reward was that 
reflection activities served as a feedback mechanism for the instructors. Many students expressed that they had learned "a lot" or "more than expected", which is an encouraging sign that they worked hard and found the project rewarding. Reflection also showed the challenges that a project like this presents to students, and changes have already been made to the project in the spring 2018 semester based on this feedback.

Transferability

Similar projects can be easily integrated in other courses or engineering disciplines. Courses that already incorporate project-based learning are good candidates, especially those with open-ended projects, since modifications can be done without altering the original learning outcomes. Once a course/project has been identified it is important to pinpoint which goals of the project could be enhanced by the service-learning component. Having clearly defined learning outcomes related to the service component item helps writing of meaningful reflection questions. Considering logistical issues is a critical part of successfully implementing a short service-learning activity like this one. Extra time should be given for completion of the project to account for the extra work associated with the service-learning component. When it comes to the community partner, instructors need to know in advance whether they will ask students to work with a specific community partner or if students will approach potential partners as in the example presented in this study. Working with partners on campus makes it easier for students and faculty to manage interactions, but instructors need to have a plan to manage these exchanges. Regardless of the type of reflection used, it is important to allow students to dedicate uninterrupted time to think and reflect about their projects without external distractions.

\section{Conclusions}

The modification to the final project in this measurements lab proved to be a simple way to introduce service-learning to engineering students without the need of major course redesign. It provided evidence that the learning outcomes of existing projects do not have to be negatively impacted by the incorporation of the service-learning component. The challenges encountered during this project were not entirely unexpected given that this was the first time the project had been implemented with the service-learning component. These challenges can be minimized by formalizing the interactions and communication with the on-campus campus community partners so that all students experience the service-learning component the same way.

\section{References}

[1] Barrington, L., Duffy, J. "Maximizing the Benefits of Service- Learning in Engineering", In ASEE 2010 Annual Conference Proceedings 2010 American Society of Engineering Education. [2] J. Eyler, "Reflection: Linking Service and Learning - Linking Students and Communities," Journal of Social Issues, vol. 58. P.517. Fall 2002.

[3] Turns, J. A., Sattler, B., Yasuhara, K., Borgford-Parnell, J. L., \& Atman, C. J. "Integrating reflection into engineering education". In 121st ASEE Annual Conference \& Exposition, Indianapolis, IN June 15-18, 2014.

[4] Thomas, L. D., Shroyer, K.E., \& Atman, C. J. “Tips \& Tricks for Successful Implementation of Reflection Activities in Engineering Education." In 123rd ASEE Annual Conference \& Exposition, New Orleans, LA June 26-29, 2016.

[5] Consortium to Promote Reflection in Engineering Education (2018). http://cpree.uw.edu/ 